\title{
Fractures of the posteromedial process of the talus
}

\author{
A report of two cases \\ M. Gutierres, T. Cabral, A. Miranda, L. Almeida \\ Department of Orthopaedic Surgery, Hospital São João, Porto, Portugal
}

Accepted: 5 June 1998

Summary. The authors present two cases of fractures of posteromedial process of talus. One was treated conservatively and the other by excision. The appearances of the CT scans, the therapeutic options and the mechanism of injury are discussed.

Résumé. Les auteurs rapportent deux cas de fractures du tubercule postero-interne de l'astragale, en réferant leur rareté et les difficultés de leur diagnostique. La première a été traitée de façon orthopedique et la deuxième a subi une excision chirurgicale du fragment. On met en évidence l'importance du TAC et on discute les traitements utilisés, aussi bien que les mécanismes de la lésion.

\section{Introduction}

The posterior process of the talus is composed of two tubercles, the lateral and medial, between which is the groove for the flexor hallucis longus tendon. This process develops from a separate ossification centre which reported may fail to fuse, forming the "os trigonum" in a incidence of from 2.7 to $7.8 \%$ [13]. The lateral tubercle, the larger of the two, projects more posteriorly than the medial and serves as the talar attachment for the posterior talofibular ligament $[5,9]$. The medial tubercle is smaller, and more difficult to recognize in the lateral X-rays. Some fibres of the deltoid ligament and those of the talocalcaneal ligament are attached to it. Cedell explained the fracture of this tubercle as an avulsion injury due to forced

Reprint requested to: M. Gutierres, Serviço de Ortopedia, Hospital de São João, Alameda Prof. Hernani Monteiro, P-4200 Porto, Portugal; Fax: +351-2-598841 dorsiflexion of the foot. This contradicts the opinion of other authors [1,3].

Unrecognized fractures of the posterior process of the talus may cause local pain as well as the tarsal tunnel syndrome [12]. Computed tomography is important in assessing the exact location, size, and displacement of this fracture, which is rare [6].

\section{Case reports}

Case 1

A 28-year-old man fell from a height of $10 \mathrm{~m}$, landing on his right foot in a plantar-flexed position. Examination revealed diffuse swelling and tenderness of the ankle. No fractures were identified in the initial radiographs, but the foot was immobilized in a short leg cast for almost 6 weeks. The cast was then removed and a rehabilitation begun, but pain remained. A CT scan was then performed and a fracture of the medial tubercle of the posterior process of the talus involving the articular surface was identified (Fig. 1). Three months after the injury, using a posteromedial approach (Fig. 2), the whole fragment was excised (Fig. 3). With 6 weeks of physiotherapy the pain disappeared and the range of motion gradually returned to normal.

\section{Case 2}

A 37-year-old man fell from a ladder, landing on a plantar-flexed left foot. Radiographs taken in the emergency room showed a fracture of the posteromedial process of the talus. The ankle was immobilized and CT was performed some days later, confirming the initial diagnosis. Because the foot was grossly swollen, it was treated conservatively with a splint for 

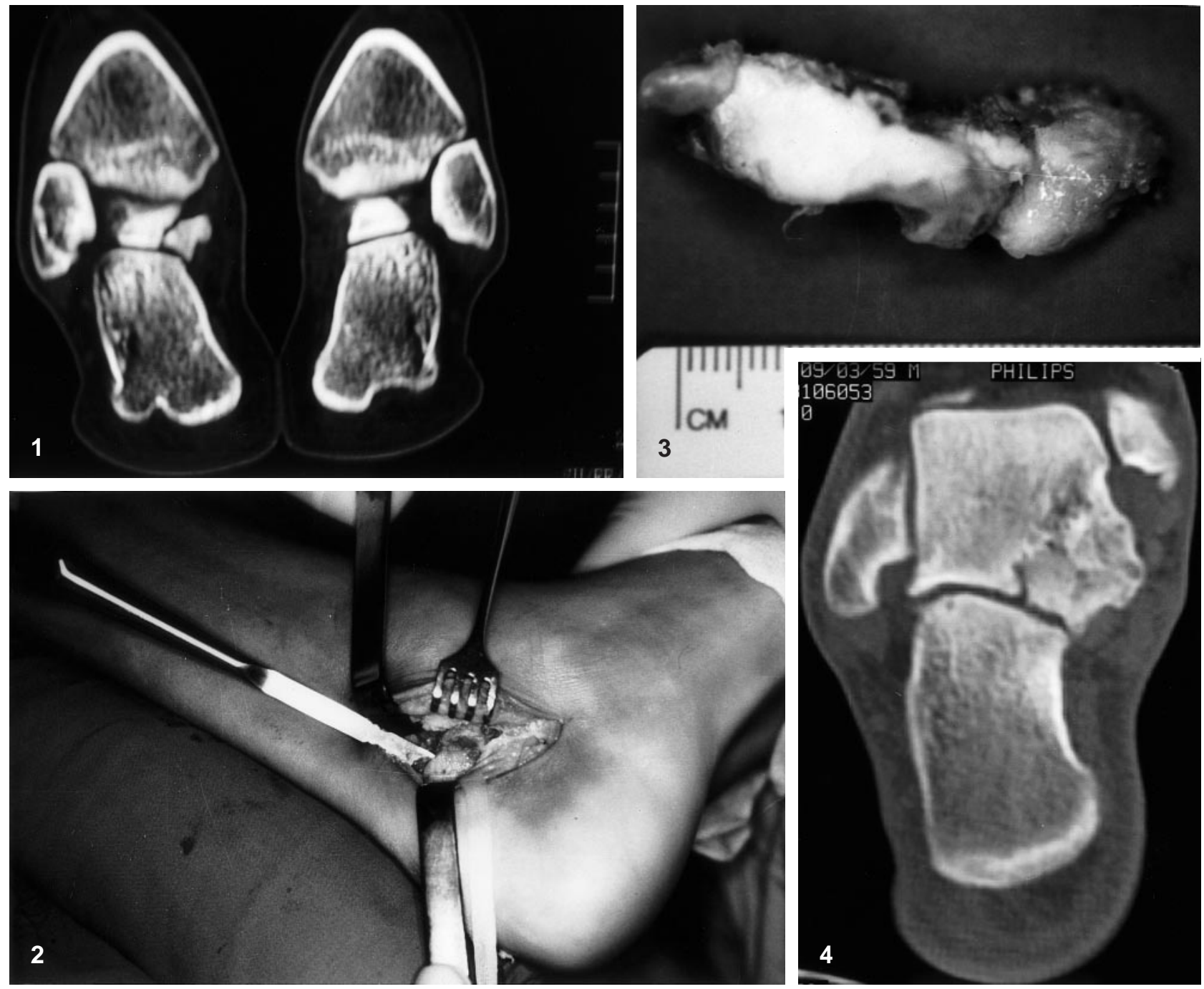

Fig. 1. CT scan showing a large displaced fragment of the posteromedial process of the talus with small articular extension

Fig. 2. Posteromedial approach reveals the position of the flexor halucis longus tendon and the fragment

Fig. 3. The excised fragment

Fig. 4. Follow-up CT scan shows partial healing of the fragment

8 weeks, followed by 2 months of physiotherapy. A gradual return to work was then allowed. The patient now has a normal range of motion and walks without pain or limp (Fig. 4).

\section{Discussion}

Lauge-Hansen [10] and Broström [2] stated that isolated rupture of the posterior talotibial ligament, a portion of the deltoid ligament, was a very rare injury. However, Cedell, in 1974, described four cases of fractures of the posteromedial process of the talus in patients with chronic medial pain and swelling in the ankle joint [3]. He described these lesions as avulsion fractures, resulting from forced dorsiflexion and pronation, but there is some controversy concerning the mechanism of injury. Cedell described it as an avul- sion mechanism, but other authors, and our two cases, suggest that this fracture can also result from direct impingement in plantar flexion.

These case reports show the need for using computed tomography in the evaluation of such fractures in order to assess the exact location, size, displacement, the degree of comminution and involvement of the subtalar joint. Knowledge of associated lesions is helpful in selecting the surgical approach.

In the first case the fracture was exposed through a posteromedial approach. The fragment was displaced more than $3 \mathrm{~mm}$ and involved the articular surface. Excision was the correct choice but larger fragments can be reduced and stabilised with a screw $[4,11]$.

When conservative treatment is undertaken initial immobilisation is required followed by a period of non-weightbearing and appropriate rehabilitation in order to obtain the best clinical result $[7,8]$. 


\section{References}

1. Banks AS, Caldarella D (1994) Fractures of the posteromedial process of the talus. J Am Pod Med Assoc 84: $66-70$

2. Broström L (1966) Sprained ankles. Dissertation. Stockholm

3. Cedell CA (1974) Rupture of the posterior talotibial ligament with the avulsion of a bone fragment from the talus. Acta Orthop Scand 45:454-461

4. Chen Y, Hsu R, Shih H, Huang T (1996) Fracture of the entire posterior process of talus associated with subtalar dislocation: a case report. Foot Ankle 17:226-229

5. Ebraheim NA, Skie MC, Podeszwa DA (1994) Medial subtalar dislocation associated with fracture of the posterior process of the talus. Clin Orthop Rel Res 33:226-230

6. Ebraheim NA, Skie MC, Podeszwa DA, Jackson WT (1994) Evaluation of process of the talus using computed tomography. J Orthop Trauma 8:332-337 1994
7. Hernandez M (1994) Fracture of the posterior process of the talus: a discussion and case presentation. Texas Med 90:57-59

8. Kim D, Hrutkay J, Samson M (1996) Fracture of the medial tubercle of the posterior process of the talus: a case report and literature review. Foot Ankle 17: 186-188

9. King RE, Powell DF (1991) Injury to the talus. In: Jahss MH (ed) Disorders of the foot and ankle, 2nd edn. Saunders, Phildelphia, p 2312

10. Lauge-Hansen N (1942) Ankelbend I. Genetisk diagnose og reposition. Dissertation Munksgaard, Copenhagen

11. Nasser S, Manoli A (1996) Fracture of the entire posterior process of the talus: a case report. Foot Ankle 10: No. 4

12. Stefko RM, Laverman WC, Heckman JD (1994) Tarsal tunnel syndrome caused by an unrecognized fracture of the posterior process of the talus (Cedell fracture). J Bone Joint Surg [Am] 76:116-118

13. Wenig JA (1990) Os trigonum syndrome. J Am Pod Med Assoc 80:278-282 